Jurnal Teknologi dan Rekayasa Sumber Data Air Vol. 1 No. 1 (2021) p. 126-135

(c) Jurusan Teknik Pengairan, Fakultas Teknik, Universitas Brawijaya

\title{
JTRESDA
}

Journal homepage: https://jtresda.ub.ac.id

\section{Estimasi Tinggi Curah Hujan dari Data Klimatologi Menggunakan Model Artificial Neural Network (Ann) di Kabupaten Badung Bali Selatan}

\author{
Muhammad Walidi Juma'a ${ }^{1 *}$, Lily Montarcih Limantara ${ }^{1}$, Sri Wahyuni ${ }^{1}$ \\ ${ }^{1}$ Jurusan Teknik Pengairan Fakultas Teknik Universitas Brawijaya, \\ Jalan MT. Haryono No. 167 Malang 65145, INDONESIA \\ *Korespondensi Email: muhammad_walidi@yahoo.com
}

\begin{abstract}
The objective of this research was to establish the results of calibration relationship between rainfall and climatology, mathematical equations and the results of the validation Artificial Neural Network (ANN) method from 30 years of climatological data and historical rainfall. The population was taken from the Meteorology, Climatology and Geophysics Agency at Ngurah Rai Station, Badung Regency, Bali. Climatic data and rainfall data were analyzed the quality of the data, namely the consistency test, stationary test, trend absence test and persistence test. The output of the analysis calculation of rainfall using the (ANN) method of observational data based on the calibration found that in the distribution of data for 25 years epoch 2000 with an indicator value of NSE $=0.83$ (Good) and $\mathrm{R}=0.91$ (Very strong) showed the best results, while for verification on 1 year epoch 2000 data with an indicator value of NSE $=0.48$ (fulfilled) and $\mathrm{R}=0.90$ (very strong). The comparison of rainfall data with observational data is almost close if the Nash-Sutchliffe Efficiency (NSE) and Correlation Coefficient (R) values meet the existing categories.
\end{abstract}

Keywords: Artificial Neural Network (ANN), Correlation Coefficient (R), NashSutchliffe Efficiency (NSE), and Rainfall.

Abstrak : Tujuan penelitian ini untuk mengetahui hasil kalibrasi hubungan curah hujan dengan klimatologi, persamaan matematis dan hasil validasi metode Artificial Neural Network (ANN) dari 30 tahun data klimatologi dan curah hujan historis. Populasi diambil dari Badan Meteorologi Klimatologi dan Geofisika di Stasiun Ngurah Rai, Kabupaten Badung, Bali. Data iklim dan data curah hujan dilakukan analisis kualitas data, yaitu dengan Uji Konsistensi, Uji Stasioner, Uji Ketidakadaan trend dan Uji Persistensi. Hasil analisis perhitungan curah hujan dengan metode (ANN) terhadap data pengamatan berdasarkan kalibrasi didapatkan bahwa di pembagian data 25 tahun epoch 2000 dengan nilai indikator NSE $=0,83$ (Baik) dan $\mathrm{R}=0,91$ (Sangat kuat) menunjukan hasil terbaik, sedangkan untuk verifikasi pada data 1 tahun epoch 2000 dengan nilai indikator NSE = 0,48 (Memenuhi) dan $\mathrm{R}=0,90$ (Sangat kuat). Perbandingan data curah hujan dengan data pengamatan hampir mendekati jika nilai Efisiensi Nash-Sutchliffe $\left(E_{N S}\right)$ dan Koefisien Korelasi $(R)$ memenuhi kategori yang ada. 
Kata Kunci : Artificial Neural Network (ANN), Curah Hujan, Efisiensi Nash-Sutchliffe (ENS), dan Koefisien Korelasi (R).

\section{Pendahuluan}

Cuaca adalah kondisi atmosfer yang terjadi dalam ruang lingkup kecil dengan kurun waktu yang singkat. Data cuaca berguna pada banyak bidang, diantaranya pertanian, penerbangan dan infrastruktur keairan. Cuaca dapat berubah-ubah karena diakibatkan oleh unsur-unsur iklim, salah satu faktor cuaca yang dapat mendeskripsikan secara umum kondisi cuaca ialah curah hujan. Curah hujan yang terbentuk tidak dapat ditentukan secara pasti tetapi dapat diperkirakan.

Prediksi cuaca yang akurat diperlukan supaya bisa menaikan produktivitas di berbagai bidang, menetukan proses perencanaan dan pengambilan keputusan. Diantaranya metode yang bisa dipakai untuk memprediksi cuaca ialah Artificial Neural Network (ANN). ANN bisa diimplementasikan dengan baik adalah dalam bidang peramalan [1].

Salah satu Algoritma ANN yang sering dipakai untuk mencari bobot optimal ialah Matlab Backpropagation. Backpropagation adalah algoritma yang memakai metode pembelajaran terawasi dan memiliki jaringan dalam tiga layar, ialah layar masukan, layar keluaran dan layar tersembunyi. Setiap layar dapat memiliki satu atau lebih neuron. Teknik ini bertujuan meminimalkan error pada keluaran yang dihasilkan jaringan dan mempersingkat waktu pengerjaan dibandingkan perhitungan metode konvensional. Dalam penelitian ini menggunakan ANN dengan metode algoritma learning Backpropagation untuk memprakiraan tinggi curah hujan dari data historis klimatologi di kawasan Kabupaten Badung Provinsi Bali. Berikut ini ialah beberapa referensi yang penyusun dapatkan dari berbagai sumber.

1. Novalina Putri Pratiwi, Sri Wahyuni, dan Ery Suhartanto tahun 2019 dengan judul Estimasi Tinggi Curah Hujan Dari Data Klimatologi Menggunakan Model Artificial Neural Network (ANN) di Kabupaten Sampang, Jawa Timur.

2. Ni Made Candra Partarini, Ery Suhartanto, dan Donny Harisuseno tahun 2019 dengan judul Validasi Data Curah Hujan TRMM (Tropical Rainfall Measuring Mission) dengan Pos Stasiun Hujan di Sub DAS Lesti.

3. Yuzy Alfahnie, Very Dermawan, Lily Montarcih Limantara tahun 2012 dengan judul Analisis Tinggi Curah Hujan Berdasarkan Kondisi Klimatologi dengan Menggunakan Jaringan Syaraf Tiruan di Karangploso, Malang, Jawa Timur. 


\section{Metodelogi Penelitian}

\subsection{Lokasi Daerah Studi}

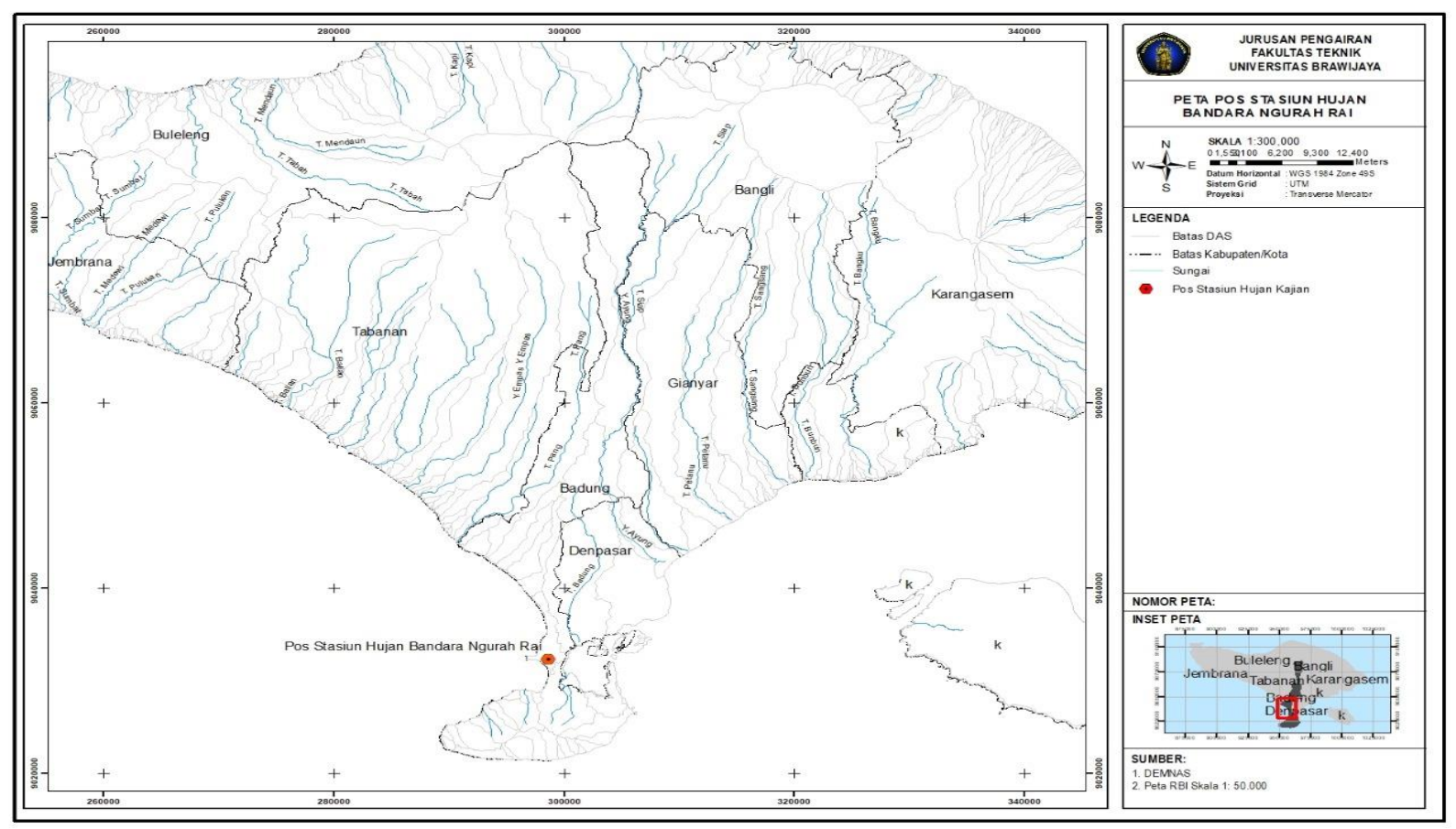

Gambar 1 : Lokasi daerah studi

Berdasarkan Gambar 1 Badung adalah kabupaten yang terletak di Provinsi Bali dan luas daerah Kabupaten Badung sebesar 418,62 $\mathrm{Km}^{2}$ yang secara administrasi terbagi atas 6 kecamatan dan 16 kelurahan. Secara geografis terletak antara $8^{\circ} 14^{\prime} 17^{\prime \prime}$ sampai $8^{\circ} 50^{\prime} 57^{\prime \prime}$ Lintang Selatan dan $115^{\circ} 05^{\prime} 02^{\prime \prime}$ sampai $115^{\circ} 15^{\prime} 09^{\prime}$ B Bujur Timur. Beda ketinggian pada satu daerah dengan daerah yang lain terlihat dari perbedaan ketinggian diatas permukaan laut antara kawasan kecamatan Petang $(2075 \mathrm{~m})$ dengan kecamatan Kuta (27 m).

\subsection{Uji Ketidakadaan Trend}

\subsubsection{Uji Korelasi Peringkat Metode Spearman}

Trend bisa dilihat sebagai hubungan waktu dengan variansi dalam suatu variabel hidrologi. Diantaranya dengan koefisien korelasi peringkat berdasarkan Metode Spearman seperti berikut [2] :

$$
\begin{aligned}
& K P=1-\frac{6 \sum_{i=l}^{n}(d t)^{2}}{n^{3}-n} \\
& t=K P\left[\frac{n-2}{1-K P^{2}}\right]^{\frac{1}{2}}
\end{aligned}
$$

\section{Dengan :}

$\mathrm{KP}=\mathrm{n}$ korelasi peringkat dari spearman

$\mathrm{n} \quad=$ total data

$\mathrm{dt} \quad=\mathrm{Rt}-\mathrm{Tt}$

$\mathrm{Tt} \quad=$ peringkat waktu

Rt $\quad=$ peringkat variabel hidrologi

$\mathrm{t} \quad=$ angka diskoefisientribusi $\mathrm{t}$, derajat kebebasan dengan tingkat kepercayaan 


\subsubsection{Uji Mann dan Whitney}

Pengujian Mann dan Whitney dilakukan untuk mengetahui satu set sempel data berurutan menjelaskan adanya trend atau tidak, sehingga dapat digunakan prosedur yang sama [3], menggunakan persamaan berikut:

$U_{1}=N_{1} N_{2}+\frac{N_{1}}{2}\left(N_{1}+1\right)-R m$

Pers. 3

$U_{2}=N_{1} N_{2}-U_{1}$

Pers. 4

$Z=\frac{\frac{U-\left(N_{1} N_{2}\right)}{2}}{\left[\frac{1}{12}\left\{N_{1} N_{2}\left(N_{1}+N_{2}+1\right\}\right]^{1 / 2}\right.}$

Pers. 5

Dengan :

$U 1, U 2=$ parameter statistik

N1 $=$ total data pada grup 1

$N 2=$ total data pada grup 2

$\mathrm{Rm} \quad=$ total nilai peringkat dari rangkaian data pada grup 1

Hipotesis nol $H O$ : grup 1 dan grup 2 berasal dari populasi yang sama

\subsection{Uji Stasioner}

\subsubsection{Uji F}

Uji statistik F menjelaskan semua variabel independen atau variabel bebas yang ditempatkan dalam model memiliki pengaruh secara keseluruhan terhadap variabel dependen atau variabel terikat[4]. Rumus uji kestabilan (Uji F) sebagai berikut :

$F=\frac{n_{1} S_{1}\left(n_{2}-1\right)}{n_{2} S_{2}\left(n_{1}-1\right)}$

Pers. 6

Dengan:

$n 1, n 2=$ jumlah data pada kelompok 1 dan 2

S1,S2 = standar deviasi pada kelompok 1 dan 2

Dengan melakukan pengujian hipotesis ini memakai statistik F untuk kriteria pengambilan keputusan diantara berikut:

$\mathrm{F}<\mathrm{Fcr}=$ maka $H O$ diterima (data homogen)

$\mathrm{F}>\mathrm{Fcr}=$ maka $H O$ ditolak (data tidak homogen)

\subsubsection{Uji T}

Uji T adalah untuk membandingkan rata-rata dua sampel. Uji $\mathrm{T}$ ini termasuk jenis pengujian pada sampel kecil. jumlah sampelnya $n<30$. Dengan mengetahui kedua sampel bersumber dari populasi yang sama[5], maka dihitung nilai $t$ dengan sebagai berikut:

$t=\frac{X_{1}-X_{2}}{\sigma\left(\frac{1}{n_{1}}+\frac{1}{n_{2}}\right)^{1 / 2}}$

Pers. 7

$\sigma=\left(\frac{n_{1} s_{1}^{2}+n_{2} S_{2}^{2}}{n_{1}+n_{2}-2}\right)^{1 / 2}$

Pers. 8

Dengan:

$\mathrm{n} 1, \mathrm{n} 2=$ jumlah data pada kelompok 1 dan 2

$\mathrm{S} 1, \mathrm{~S} 2=$ standar deviasi pada kelompok 1 dan 2

$\mathrm{X} 1, \mathrm{X} 2=$ rata-rata pada kelompok 1 dan 2

Hipotesa: 
H0 : kelompok 1 dan kelompok 2 bersumber dari populasi yang serupa

H1 : kelompok 1 dan kelompok 2 tidak bersumber dari populasi yang serupa

\subsection{Uji Persistensi}

Persistensi mempunyai arti ketidaktergantungan dari setiap nilai dalam deret berurutan. Pada uji persistensi ini digunakan dengan metode spearman untuk menghitung besarnya koefisien korelasi seri berikut ini [1] :

$K S=1-\frac{6 \sum_{i=l}^{m}(d t)^{2}}{m^{3}-m}$

Pers. 9

$t=K S\left[\frac{m-2}{1-K S^{2}}\right]^{\frac{1}{2}}$

Pers. 10

Dengan :

$K S \quad=$ koefisien korelasi serial

$m \quad=n-1$

$n \quad=$ total data

$d i \quad=$ selisih nilai antar peringkat data ke $\mathrm{Xi}$ dan $\mathrm{ke} \mathrm{Xi}+1$

$t \quad=$ nilai pada distribusi-t dari derajat kepercayaan $\mathrm{m}-2$ dan derajat kebebasan tertentu (lazimnya 95\% diterima atau, $5 \%$ ditolak)

\subsection{Uji Konsistensi}

Uji Konsistensi merupakan menguji keabsahan data pengamatan langsung yang tidak terpengaruh oleh kesalahan pada saat pengukuran, data itu mesti benar menunjukkan kejadian hidrologi sesuai kondisi sebenarnya di lapangan. Dapat diartikan data hidrologi dinyatakan tidak konsisten bila ada perbedaan diantara nilai pengukuran dengan nilai sebenarnya[6].

$\mathrm{S}^{*} \mathrm{o}=0$

$S * k=\sum_{i=1}^{K}(Y i-Y)$

Pers. 11

Dengan :

$\mathrm{K}=1,2,3, \ldots \ldots, \mathrm{n}$

$\mathrm{S}^{*} \mathrm{O}=$ Simpangan awal

$\mathrm{S} * \mathrm{k} \quad=$ Simpangan mutlak

$\mathrm{n} \quad=$ Total data

$S * k=\frac{S * k}{D y}$

Pers. 12

$D y^{2}=\frac{\sum_{i=1}^{k}(Y i-Y)^{2}}{n}$

Pers. 13

Nilai Statistik Q dan R

$\mathrm{Q}=$ maksimal $\left|\mathrm{S}^{* *} \mathrm{k}\right|$

Pers. 14

$\mathrm{R}=$ maksimal $\left|\mathrm{S}^{* *} \mathrm{k}\right|-$ minimal $\mathrm{S}^{* *} \mathrm{k}$

Pers. 15

Dengan :

$\mathrm{S}^{* * \mathrm{k}}=$ Nilai konsistensi data

Dy = Simpangan rata-rata

$\mathrm{Q} \quad=$ Nilai statistik Q untuk $0 \leq \mathrm{k} \leq \mathrm{n}$

$\mathrm{R}=$ Nilai statistik (range)

Dengan nilai statistik $\mathrm{Q}$ dan $\mathrm{R}$ maka bisa didapatkan $\mathrm{Q} / \sqrt{ }_{\mathrm{n}}$ dan $\mathrm{R} / \sqrt{ } \mathrm{n}$, sehingga dapat diketahui apakah data dinyatakan konsisten atau tidak. 


\subsection{Matlab}

Matlab ialah bahasa dengan (high-performance) performa tinggi untuk komputasi pada bidang teknik. Matlab mengoperasikan komputasi, visualisasi, dan pemrograman pada model yang sangat gampang untuk dipakai dalam masalah-masalah dan penyelesaiannya dijabarkan dalam notasi matematika yang dikenal[7].

\subsection{Artificial Neural Network}

Artifical Neural Network (ANN) ialah sebuah gambaran pada otak manusia yang selalu meniru cara pembelajaran dari otak manusia[8]. Backpropagation ialah algoritma pembelajaran terawasi dan umumnya dipakai oleh perceptron yang memiliki banyak layar untuk mengubah bobot yang terkorelasi dengan neuron yang ada dalam layar tersembunyi[8].

\subsection{Kalibrasi}

Kalibrasi terhadap model ialah proses memilih gabungan parameter yaitu proses dimana untuk memaksimalkan nilai dalam sebuah parameter untuk mengoptimalkan koherensi antar respons hidrologi DAS yang dapat diamati dengan yang tersimulasi. Koherensi (keakuratan antar yang terukur dengan yang terhitung) dilihat secara kualitatif, contohnya membandingkan hidrograf debit terukur dan terhitung [9].

\subsection{Verifikasi}

Verifikasi adalah proses setelah tahap kalibrasi digunakan yang memiliki fungsi untuk mengevaluasi kinerja model dari data diluar periode kalibrasi. Kinerja model umumnya lebih baik pada periode kalibrasi dibandingkan dengan metode verifikasi, hal ini disebut divergensi model[10].

\subsection{Validasi}

Validasi adalah proses evaluasi kepada model untuk memiliki gambaran akan tingkat ketidakpastian yang dimiliki suatu model dalam memperkirakan proses hidrologi. Biasanya validasi digunakan dengan memakai data diluar periode data yang dipakai untuk kalibrasi[11].

\subsection{Analisis Kesesuaian Metode}

\subsubsection{Uji Efisiensi Nash-Sutcliffe}

Uji Efisiensi Nash-Sutcliffe merepresentasikan seberapa baik plot nilai pengukuran dibandingkan dengan nilai estimasi atau prediksi, dimana Uji Efisiensi Nash-Sutcliffe memiliki range antara negatif tak terhingga sampai dengan 1. Uji ini bertujuan untuk mengevaluasi kesahihan pada model. Rumus ini untuk mengitung Nash-Sutcliffe sebagai berikut:

$E_{N S}=1-\frac{\sum_{i=1}^{n}(X-Y)^{2}}{\sum_{i=1}^{n}(X-X)^{2}}$

Pers. 16

Keterangan:

$\mathrm{X}=$ Data Pengamatan

$\mathrm{Y} \quad=$ Data Model

$X=$ Data Pengamatan Rata-rata

$\mathrm{N}=$ Jumlah Data 


\subsubsection{Uji Koefiensi Korelasi}

Koefisien korelasi adalah salah satu metode statistik yang biasa digunakan untuk melihat hubungan antar kedua veriabel (hasil pengamatan dengan hasil perhitungan). Tujuan analisa ini untuk mendapatkan pola dan keeratan hubungan antar variabel. Rumus untuk mengetahui koefisien korelasi yaitu:

$R=\frac{n \sum_{i=1}^{n} X Y-\left(\sum_{i=1}^{n} X\right)\left(\sum_{i=1}^{n} Y\right)}{\sqrt{\left(n \sum_{i=1}^{n} X^{2}-\left(\sum_{i=1}^{n} X\right)^{2}\right)\left(n \sum_{i=1}^{n} Y^{2}-\left(\sum_{i=1}^{n} Y\right)^{2}\right)}}$

Pers. 17

Keterangan :

$\mathrm{X}=$ Data Pengamatan

$\mathrm{Y} \quad=$ Data Model

$\mathrm{N} \quad=$ Jumlah Data

\subsubsection{Uji Root Mean Squared Error (RMSE)}

Indikator yang digunakan pada metode ini berupa kesalahan yang didasarkan dari total kuadratis dari simpangan antara hasil model dan pengamatan. Uji Root Mean Square Error (RMSE) bertujuan untuk mengetahui keakuratan dari hasil permodelan dengan data pengamatan yang dimiliki. Rumus untuk mengetahui nilai Root Mean Square Error (RMSE) adalah sebagai berikut :

$R M S E=\sqrt{\frac{\sum_{i=1}^{n}(X-Y)^{2}}{n}}$

Pers. 18

Keterangan:

$\mathrm{X}=$ Data Pengamatan

$\mathrm{Y} \quad=$ Data Model

$\mathrm{N}=$ Jumlah Data

\section{Hasil dan Pembahasan}

3.1 Uji Kualitas

Tabel 1 : Hasil Uji Kualitas Data

\begin{tabular}{|c|c|c|c|c|c|c|c|c|c|c|c|}
\hline \multirow{2}{*}{\multicolumn{2}{|c|}{ Uji Kualitas Data }} & \multicolumn{2}{|c|}{$\begin{array}{l}\text { Curah } \\
\text { Hujan }\end{array}$} & \multicolumn{2}{|c|}{$\begin{array}{c}\text { Kecepatan } \\
\text { Angin }\end{array}$} & \multicolumn{2}{|c|}{$\begin{array}{c}\text { Lama } \\
\text { Penyinaran }\end{array}$} & \multicolumn{2}{|c|}{$\begin{array}{l}\text { Suhu } \\
\text { Udara }\end{array}$} & \multicolumn{2}{|c|}{ Kelembapan } \\
\hline & & $5 \%$ & $1 \%$ & $5 \%$ & $1 \%$ & $5 \%$ & $1 \%$ & $5 \%$ & $1 \%$ & $5 \%$ & $1 \%$ \\
\hline \multirow{2}{*}{ Uji Stasioner } & Uji F & $\sqrt{ }$ & $\sqrt{ }$ & $\sqrt{ }$ & $\sqrt{ }$ & $\sqrt{ }$ & $\sqrt{ }$ & $\sqrt{ }$ & $\sqrt{ }$ & $\mathrm{x}$ & $\sqrt{ }$ \\
\hline & $\mathrm{Uji} \mathrm{T}$ & $\sqrt{ }$ & $\sqrt{ }$ & $\sqrt{ }$ & $\sqrt{ }$ & $\sqrt{ }$ & $\sqrt{ }$ & $\sqrt{ }$ & $\sqrt{ }$ & $\sqrt{ }$ & $\sqrt{ }$ \\
\hline \multirow{2}{*}{$\begin{array}{l}\text { Uji Ketiadaan } \\
\text { Trend }\end{array}$} & Uji Spearman & $\sqrt{ }$ & $\sqrt{ }$ & $\mathrm{X}$ & $\mathrm{x}$ & $\mathrm{X}$ & $\mathrm{X}$ & $\sqrt{ }$ & $\sqrt{ }$ & $\mathrm{x}$ & $\mathrm{X}$ \\
\hline & $\begin{array}{c}\text { Uji Mann- } \\
\text { Whitney }\end{array}$ & $\sqrt{ }$ & $\sqrt{ }$ & $\mathrm{X}$ & $\sqrt{ }$ & $\sqrt{ }$ & $\sqrt{ }$ & $\sqrt{ }$ & $\sqrt{ }$ & $\mathrm{x}$ & $\sqrt{ }$ \\
\hline Uji Persistensi & $\begin{array}{c}\text { Metode } \\
\text { Spearman }\end{array}$ & $\mathrm{x}$ & $\mathrm{X}$ & $\mathrm{X}$ & $\mathrm{X}$ & $\mathrm{X}$ & $\mathrm{x}$ & $\mathrm{X}$ & $\mathrm{x}$ & $\mathrm{x}$ & $\mathrm{X}$ \\
\hline
\end{tabular}

Keterangan:

Diterima $: \sqrt{ }$

Ditolak $\quad: \mathrm{x}$ 
Berdasarkan Tabel 1 data yang digunakan diterima pada uji stasioner dan ketiadaan trend, namun uji persistensi ditolak. Uji konsistensi pada data curah hujan menunjukan diterima, maka data dapat digunakan untuk analisis hidrologi lanjutan/permodelan.

Setelah melakukan uji kualitas data dilanjutkan dengan analisis ANN (Artificial Neural Network). Analisis ini menggunakan data 30 tahun (1990-2019) dengan komposisi 25-5 tahun, 26-4 tahun, 27-3 tahun, 28-2 tahun dan 29-1 tahun. Selain itu, epoch yang dipakai 1000, 1500 dan 2000. Dengan metode trial and error dicari jaringan yang paling sesuai untuk data yang digunakan.

Setelah didapat jaringan yang paling sesuai dari hasil analisis ANN dilanjutkan persamaan matematis pada jaringannya, persamaan matematis menggunakan rumus dasar ANN berdasarkan jaringan hasil analisis ANN. Maka didapat rumus sebagai berikut :

y_ch $=\left(1-\exp \left(\sum_{c=1}^{C} \sum_{d=1}^{D} W_{h l-o l}\right.\right.$ cd.$\left(1-\exp \left(\sum_{a=1}^{A} \sum_{b=1}^{B} W_{i-h l \_} \mathrm{ab} . \mathrm{X}_{\mathrm{su}}+W_{i-h l-a b} . \mathrm{X}_{\mathrm{ku}}+\right.\right.$ Dengan:

y_ch = output curah hujan

$X \quad=$ besaran nilai variabel input

$W_{m n} \quad=$ matriks bobot layer $-\mathrm{m}$ ke layer $-\mathrm{n}$

$B_{n} \quad=$ matriks bias layer $-\mathrm{n}$

Kemudian hasil analisis ANN dilanjutkan dengan hasil validasinya. Pada hasil kalibrasi berdasarkan Tabel 2 menunjukan perbedaan yang tidak signifikan antara data 25 tahun (1990-2014) sampai data 29 tahun (1990-2018), tetapi data 25 tahun (1990-2014) di epoch 2000 yang memiliki nilai paling optimal dengan validasi nilai NSE dan R yang paling mendekati 1, dan nilai RMSE terendah. Pada hasil verifikasi berdasarkan Tabel 3 menunjukan data 1 tahun (2019) di epoch 2000 yang memiliki nilai paling optimal dengan validasi nilai NSE yang paling mendekati 1, dan nilai RMSE terendah.

Berdasarkan hasil penelitian ini bahwa panjang data pada uji kalibrasi belum tentu menghasilkan nilai memenuhi dan kuat pada uji verifikasi, sedangkan kecenderungan uji validasi membutuhkan data yang lebih panjang untuk mendapatkan nilai yang memenuhi dan kuat. Biasanya semakin panjang data yang dipakai pada tahap validasi akan mendapatkan data model lebih baik, akan tetapi dalam kasus ini berbeda. Disebabkan dari faktor range yang dimana dapat mempengaruhi hasil data model dan nilai error dengan bukti adanya persistensi (ketidaktergantungan) di data. Oleh karena itu, uji ketiadaan trend dan persistensi masih relevan digunakan pada penelitian ini. 
3.2 Uji Validasi

Tabel 2 : Uji Validasi Hasil Kalibrasi

\begin{tabular}{|c|c|c|c|}
\hline \multicolumn{4}{|c|}{ DATA 25 TAHUN (1990-2014) } \\
\hline $\mathrm{EPOCH}$ & RMSE & NSE & $\mathrm{R}$ \\
\hline 1000 & 75,08 & 0,82 & 0,91 \\
\hline 1500 & 76,99 & 0,81 & 0,90 \\
\hline 2000 & 71,82 & 0,83 & 0,91 \\
\hline \multicolumn{4}{|c|}{ DATA 26 TAHUN (1990-2015) } \\
\hline $\mathrm{EPOCH}$ & RMSE & NSE & $\mathrm{R}$ \\
\hline 1000 & 76,59 & 0,81 & 0,90 \\
\hline 1500 & 75,88 & 0,81 & 0,90 \\
\hline 2000 & 79,73 & 0,79 & 0,89 \\
\hline \multicolumn{4}{|c|}{ DATA 27 TAHUN (1990-2016) } \\
\hline EPOCH & RMSE & NSE & $\mathrm{R}$ \\
\hline 1000 & 78,61 & 0,80 & 0,89 \\
\hline 1500 & 75,80 & 0,81 & 0,90 \\
\hline 2000 & 77,47 & 0,80 & 0,90 \\
\hline \multicolumn{4}{|c|}{ DATA 28 TAHUN (1990-2017) } \\
\hline $\mathrm{EPOCH}$ & RMSE & NSE & $\mathrm{R}$ \\
\hline 1000 & 78,06 & 0,80 & 0,90 \\
\hline 1500 & 83,40 & 0,77 & 0,88 \\
\hline 2000 & 78,17 & 0,80 & 0,90 \\
\hline \multicolumn{4}{|c|}{ DATA 29 TAHUN (1990-2018) } \\
\hline $\mathrm{EPOCH}$ & RMSE & NSE & $\mathrm{R}$ \\
\hline 1000 & 78,62 & 0,80 & 0,89 \\
\hline 1500 & 75,82 & 0,81 & 0,90 \\
\hline 2000 & 82,41 & 0,78 & 0,88 \\
\hline
\end{tabular}

Tabel 3 : Uji Validasi Hasil Verifikasi

\begin{tabular}{|c|c|c|c|}
\hline \multicolumn{4}{|c|}{ DATA 5 TAHUN (2015-2019) } \\
\hline $\mathrm{EPOCH}$ & RMSE & NSE & $\mathrm{R}$ \\
\hline 1000 & 208,87 & $-1,63$ & 0,28 \\
\hline 1500 & 195,03 & $-1,30$ & 0,32 \\
\hline 2000 & 181,72 & $-0,99$ & 0,38 \\
\hline \multicolumn{4}{|c|}{ DATA 4 TAHUN (2016-2019) } \\
\hline $\mathrm{EPOCH}$ & RMSE & NSE & $\mathrm{R}$ \\
\hline 1000 & 212,03 & $-1,81$ & 0,30 \\
\hline 1500 & 169,23 & $-0,79$ & 0,52 \\
\hline 2000 & 176,55 & $-0,95$ & 0,53 \\
\hline \multicolumn{4}{|c|}{ DATA 3 TAHUN (2017-2019) } \\
\hline $\mathrm{EPOCH}$ & RMSE & NSE & $\mathrm{R}$ \\
\hline 1000 & 173,32 & $-1,12$ & 0,55 \\
\hline 1500 & 157,28 & $-0,75$ & 0,62 \\
\hline 2000 & 148,71 & $-0,56$ & 0,76 \\
\hline \multicolumn{4}{|c|}{ DATA 2 TAHUN (2018-2019) } \\
\hline $\mathrm{EPOCH}$ & RMSE & NSE & $\mathrm{R}$ \\
\hline 1000 & 237,40 & $-3,80$ & 0,30 \\
\hline 1500 & 107,46 & 0,02 & 0,81 \\
\hline 2000 & 160,67 & $-1,20$ & 0,72 \\
\hline \multicolumn{4}{|c|}{ DATA 1 TAHUN (2019) } \\
\hline $\mathrm{EPOCH}$ & RMSE & NSE & $\mathrm{R}$ \\
\hline 1000 & 98,18 & 0,26 & 0,83 \\
\hline 1500 & 88,87 & 0,39 & 0,94 \\
\hline 2000 & 82,33 & 0,48 & 0,90 \\
\hline
\end{tabular}

\section{Kesimpulan}

Berlandaskan analisis perhitungan metode yang telah dilaksanakan seperti pada rumusan masalah di penelitian ini, Estimasi dari data klimatologi pada proses kalibrasi menggunakan data selama 30 tahun, menunjukan bahwa hasil terbaik dari proses kalibrasi 25 tahun (1990-2014) epoch 2000 dengan nilai indikator NSE = 0,83 (Baik), RMSE = 71,82 dan $\mathrm{R}=0,91$ (Sangat kuat).

Estimasi dari data klimatologi pada proses validasi menggunakan data selama 30 tahun, menunjukan bahwa hasil terbaik dari proses verifikasi 1 tahun (2019) epoch 2000 dengan nilai indikator NSE $=0,48$ (Memenuhi), $\mathrm{RMSE}=82,33$ dan $\mathrm{R}=0,90$ (Sangat kuat). 
Sehingga hasil validasi curah hujan dengan data klimatologi menggunakan ANN adalah memenuhi dan sangat kuat.

\section{DAFTAR PUSTAKA}

[1] Setiawan, Wahyudi. Prediksi Harga Saham Menggunakan Jaringan Syaraf Tiruan Multilayer Peedforward Network dengan Algoritma Backpropagation. Bali: Konferensi Nasional Sistem dan Informatika, 2008.

[2] Limantara, Lily Montarcih. Rekayasa Hidrologi. Yogyakarta: CV Andi Offset, 2018.

[3] Soewarno. Analisis Data Hidrologi Menggunakan Metode Statistika dan Stokastik. Yogyakarta : Graha Ilmu, 2015.

[4] Ghozali, Imam. Aplikasi Analisis Multivariate dengan Program SPSS. Semarang: UNDIP, 2009.

[5] Sarwono, J. Teori dan Praktik Riset Pemasaran dengan SPSS. Yogyakarta: Andi Yogyakarta, 2005.

[6] Soewarno. Hidrologi Aplikasi Metode statistik untuk analisa data Jilid 2. Bandung: Nova, 1995.

[7] The Math Works., Mathematical Computing Software. www.mathworks.com, 1984.

[8] Kusumadewi, Sri. Artificial Intelligence (Teknik dan Aplikasinya). Yogyakarta: Graha Ilmu, 2003.

[9] Indarto. Hidrologi Dasar Teori dan Contoh Aplikasi Model Hidrologi. Jakarta : Bumi Aksara, 2010.

[10] Pechlivanidis, I.G., Jackson, B.M., Mcintyre, N.R., \& Wheater, H.S. (2011). Catchment Scale Hydrological Modelling : A Review of Model Types, Calibration Approaches and Uncertainty Analysis Methods in the Context Of Recent Developments in Technology and Applications. Global Nest Journal. 13: 193-214.

[11] Indarto. Hidrologi Dasar Teori dan Contoh Aplikasi Model Hidrologi. Jakarta: PT Bumi Aksara, 2012. 